\title{
Deciding on the timing of early public childcare in Germany. An application of rational choice theory.
}

\author{
Hannah Steinberg \\ Corinna Kleinert \\ Leibniz Institute for Educational Trajectories, Bamberg
}

E-mail address of corresponding author:

hannah.steinberg@lifbi.de 


\title{
Deciding on the timing of early public childcare in Germany. An application of rational choice theory.
}

\begin{abstract}
This study investigates some of the mechanisms, which lead to social inequalities in the usage of early childhood education and care (ECEC) by focusing on a recent period of public childcare expansion in Germany. Based on sociological rational educational decision models, we model the decision to use ECEC as a rational cost-benefit investment strategy, which simultaneously affects the human capital of mothers and children. We test our assumptions with data from the new-born cohort of the German National Educational Panel Study (NEPS-SC1), estimating event history models. Results indicate that cost-benefit calculations are indeed relevant for the timing of ECEC take-up, but do not explain social differences. Mothers who perceive ECEC take-up as an investment into child development and as an opportunity to maintain their own occupational status take up ECEC earlier. This association is particularly pronounced for highly educated mothers. Moreover, differences for East and West Germany highlight the importance of the cultural context for cost-benefit considerations.
\end{abstract}

\section{Keywords}

educational decision; early childcare; ECEC; rational cost-benefit consideration; heterogeneous effects; family policy 


\section{Introduction}

Since 2005, the German government has expanded the provision of public childcare for children under three years (e.g., Day Expansion Act in 2005 - Tagesbetreuungsausbaugesetz; Child and Youth Welfare Act in 2008 - Kinderförderungsgesetz). As a result, childcare attendance ratios have increased in recent years and childcare usage starts nowadays from an earlier age on. From 2006 to 2017, childcare attendance rates among children under age three increased from 8 percent to 29 percent in West Germany and from 39 percent to 51 percent in East Germany. These figures show childcare availability mostly raised in West Germany while East Germany already started at a higher level (Bundesministerium für Familie, Senioren, Frauen und Jugend [BMFSFJ], 2018).

In general, public childcare should facilitate the reconciliation of family and work. Given comparatively long employment interruptions and low labour supply of mothers after birth, the childcare reform in Germany aimed at not only at increasing maternal employment but also to shorten employment interruptions after childbirth.

A further aim of the childcare expansion in Germany was to promote equal educational opportunities for all children from an early age. This interest is inspired by a growing body of literature which stress the importance of early childhood education. Research shows that early childhood education and care (ECEC) has the potential to stimulate children's cognitive and language skills especially for young children from potentially disadvantaged families (Anderson et al., 2003; Burger, 2010; Côté, Doyle, Petitclerc and Timmins, 2013; Geoffroy et al., 2010; Loeb, Bridges, Bassok, Fuller and Rumberger, 2007; Magnuson, Meyers, Ruhm and Waldfogel, 2016; Sylva, Stein, Leach, Barnes and Malmberg, 2011). Thus, early childhood education receives an increasing attention more recently.

Although childcare capacities for children under three have increased, not all children seem to profit similarly from the expansion especially because demand of public childcare still exceeds supply in many regions (BMFSFJ, 2018). Thus, a recurring finding from previous research shows that highly educated mothers are not only more likely to take up early childhood education and care (ECEC) and use it at earlier age, but also take-up ECEC for longer hours compared to low-educated mothers, single mothers or parents with a migration background (Bainbridge, Meyers, Tanaka and Waldfogel, 2005; Büchner and Spiess, 2007; Schober and Spiess, 2013; Schober and Stahl, 2014).

The underlying mechanisms which lead to social disparities in ECEC take-up are not well understood. This paper contributes to this research gap by modelling the decision to use public childcare as a rational cost-benefit investment strategy which simultaneously affects the human capital of mothers and children. Following this, we examine whether social inequalities in timing of ECEC take-up can be explained due to different perceptions of costs and benefits. Furthermore, we assume that social status groups vary with regard to childcare preferences, economic and social resources, job and childcare opportunities and in speed of adaption to societal and institutional changes. Thus, with the respect to Germany, we focus on East-West disparities as a central dimension of social and cultural differences in ECEC usage. We exploit these variations to examine the relationship between cost-benefit considerations and timing of ECEC take-up by comparing mothers born in East or West Germany. To sum up, this paper attempts to answer the following research questions: 
I. Do different cost-benefit perceptions of ECEC explain inequalities in the timing of ECEC take-up in Germany?

II. Do direct effects of cost-benefit perceptions of ECEC take-up vary among different social groups in Germany?

We test our questions with data from the new-born cohort of the National Educational Panel Study (NEPS-SC1) ${ }^{1}$, which started in 2012 with a representative sample of 3,418 children born in Germany. The first interview was conducted in 2012/13 when infants were 6-8 months old. Parents and children were followed up yearly. Each wave consists of interviews with one parent as well as video-taped measurements of child-parents interaction, experimental tasks and tests (Hachul et al., 2019). The data provide detailed information on respondents' socioeconomic background, public and informal childcare usage as well as the perception of ECEC cost and benefit aspects, which were developed specifically for this study (Stocké, Blossfeld, Hoenig and Sixt, 2019). To estimate the first take-up of an institutional ECEC setting we apply discrete event history models with a logistic link function.

This paper is structured as follows: Section 2 presents an overview of the state of research focusing especially on the relationship between dimensions relating to RC context and ECEC usage. Section 3 addresses the data, variables and the empirical strategy of this paper. In section 4, empirical results are presented and conclusions are drawn in the final section 5.

\section{Overview of previous research}

A large branch of literature focused on economic factors to explain the use of public childcare. Such factors include mother's level of educational attainment, family or maternal income as well as costs of childcare, which can be regarded as indirect measurements or antecedence conditions of the sociological RC parameters.

Generally, findings suggest that the use of childcare services is more common among families with higher educated mothers in the US (Coley, Votruba-Drzal, Collins and Miller, 2014; Crosnoe, Purtell, Davis-Kean, Ansari and Benner, 2016) as well as in European countries (Petitclerc et al., 2017; Zachrisson, Janson and Nærde, 2013). Furthermore, children with highly educated mothers attend childcare at younger ages (Petitclerc et al., 2017) and also spend more hours in ECEC settings (Early and Burchinal, 2001). Educational differences regarding childcare usage are also found in the German context: Low-educated mothers tend to enroll their children at older ages or do not register them at all (Büchner and Spiess, 2007; Krapf, 2014; Kreyenfeld and Krapf, 2016; Schober and Spiess, 2013; Schober and Stahl, 2014; Stahl and Schober, 2018). Also, children with a low-educated main caregiver experience lower quality in childcare institutions for children aged over three (Stahl, Schober and Spiess, 2018).

The results on educational disparities in ECEC take-up are in line with the RC perspective, assuming that higher educational attainment increases mothers' opportunity costs of staying at home. Due to the positive correlation between education, employment and income mothers with higher human capital face a greater reduction of already undertaken

\footnotetext{
1 This paper uses data from the National Educational Panel Study (NEPS): Starting Cohort Newborns, doi:10.5157/NEPS:SC1:4.0.0. From 2008 to 2013, NEPS data was collected as part of the Framework Program for the Promotion of Empirical Educational Research funded by the German Federal Ministry of Education and Research (BMBF). As of 2014, NEPS is carried out by the Leibniz Institute for Educational Trajectories (LIfBi) at the University of Bamberg in cooperation with a nationwide network.
} 
investments as well as higher forgone earnings when caring at home. Therefore, they have a higher incentive of taking up public childcare early and keeping labor market interruptions short compared to their less educated counterparts.

Focusing on the childcare expansion in Germany, a recent study by Stahl and Schober (2018) shows that public childcare take-up for children under the age of three most strongly increased among more educated mothers with widening gaps especially between 2007 and 2013. The circumstance that parents in employment, which positively correlates with education, enjoyed a prioritized access from 2005 to 2013 may intensified educational discrepancies over the last years. Moreover, regarding public childcare usage Stahl and Schober (2018) demonstrate a growing similarity between East and West Germany while in both regions highly skilled mothers benefitted more from the childcare expansion than lowskilled ones. The authors suggest that lower job prospects in East Germany lead to adaptions to the work-care-culture of West Germany, especially among low-educated mothers.

Despite this economic view some studies try to explain heterogeneous effects on childcare take-up with differences in cultural norms or attitudes towards institutional childcare usage and maternal employment (van Gameren and Ooms, 2009). Results from Germany demonstrate a general higher agreement with the concern over a preschool child suffering from a working mother among low-educated women compared to women with a higher level of educational attainment. These attitudinal differences are also reflected in more conservative attitudes of parents in West German compared with East Germany, two contexts with persistent variations in cultural acceptance of maternal employment and using of public childcare (Stahl and Schober, 2018). We exploit theses regional variation within Germany to investigate whether they moderate the relationship between the perception cost-benefit parameters of childcare and the timing of childcare differently.

In case of household income some studies point to a curvilinear relationship between childcare usage and income (Dowsett, Huston and Imes, 2008; NICHD Early Child Care Research Network, 1997). This association is especially relevant in the Anglo-American context where special programs foster childcare usage of potentially disadvantaged families and thus low-income families get access to publicly-supported programs while high-income families have the economic resources to pay for private childcare, whereas middle class income families struggle to afford expensive ECEC programs. Studies from European countries (Del Boca, Locatelli and Vuri, 2005; Sylva, Stein, Leach, Barnes and Malmberg, 2007) however, as well as from Germany (Büchner and Spiess, 2007; Schober and Spiess, 2012) cannot confirm this result. Contrary, some of these studies find rather a linear association between income and the probability of ECEC take-up (Büchner and Spiess, 2007; Coley et al., 2014; van Gameren and Ooms, 2009) indicating that higher opportunity costs of staying at home support the ECEC usage of young children.

Studies focusing on the effect of childcare costs have mainly analyzed the relationship between childcare decisions and maternal employment showing a positive association between costs and maternal employment especially for the Anglo-American context (Morrissey, 2017). In the German context, costs have been found to be less influential for maternal work-care decisions (Wrohlich, 2011). This finding is not surprising since although expenditures for childcare vary due to differences in federal states' subsidies as well as a fee structure which accounts for parental income, childcare costs in Germany are low in international comparison (Spiess, Berger and Groh-Samberg, 2008). Nevertheless, according 
to a 2017 study German parents evaluate childcare costs as the most critical aspect regarding the satisfaction with ECEC services (BMFSFJ2018).

We consider childcare costs by focusing on parents' perception of financial costs. Thus, we also take previous critical voices on framing ECEC take-up as rational choice into account (Chaudry, Henly and Meyers, 2010; Meyers and Jordan, 2006). Accordingly, childcare decisions are rather an accommodation to market, family, social networks and structures than isolated rational choices, due to the fact that parents lack sufficient information about childcare quality, convenience, costs of alternatives, and own preferences. Therefore, childcare choices are presumed to reflect only information, resources, and alternatives that are available for parents at the decision making time.

We contribute to this discussion by modelling subjective perceptions of costs and benefits directly. Sociological decision models account for imperfect information by expecting that differences in economic, cultural and social resources, in turn, lead to differences in the perceptions of costs and benefits, which then result in dissimilar educational decisions. Thus, we assume that mothers start ECEC take-up earlier the more they perceive positive developmental effects of childcare as well as positive occupational advantages due to ECEC; while mothers start ECEC take-up later the more they perceive the financial as well the social costs to be high. Based on these assumptions the present study extends the literature by ascertaining the effect of perceived rational cost-benefit calculations on ECEC enrolment.

\section{Research design}

\subsection{Data}

We test our assumptions with data of the birth cohort study of the German National Educational Panel Study (NEPS-SC1) (Blossfeld and Rossbach, 2019). The birth cohort study started in 2012 with a register-based probability sample of 3,418 children born in Germany between February and July 2012. The first wave of interviews in 2012/2013 was conducted, when infants were 6-8 months old. The second wave took place at the age of 12-17 months. Afterwards parents and children were followed up yearly. Each wave consisted of computerassisted interviews with one parent as well as video-based observations at the homes of the selected families. These direct measurements at the children's home include for example child-parents interactions, experimental tasks, and child's tests (Hachul et al., 2019).

\subsection{Method}

To estimate the timing of ECEC entry we apply event history analysis (Allison, 1982). This allows us to handle right-censored observations in the data as well as to consider time-varying covariates. It models the probability that an event of interest occurs in each time period, given that the event did not occur in an earlier period. The conditional probability of this so called hazard is known as the hazard function. We estimate hazard functions of the probability of ECEC take-up. ${ }^{2}$

\footnotetext{
${ }^{2}$ In Germany, owing to the discrepancy between demand and supply of public childcare parents often switch to family day care especially the younger the child is. Accordingly, we assume that for parents' majority using a childminder can be seen as a substitute for public childcare and is used only up to an ECEC registration is
} 
Moreover, we apply discrete time models with a logistic link function using monthly intervals. Beginning of ECEC usage is usually a discrete process, meaning that entry processes take place in certain months of the year and leading to a situation where many people experience an event at the same recorded time. Therefore the logistic link function is well suited for our analyses since it considers processes that are not only discretely measured but also discrete in nature (Allison, 2010; Singer and Willett, 2003). Thus, employing logistic models with clustered standard errors enables us to estimate the probability of ECEC take-up for each of the observed time period.

We define our dependent variable as the first take-up of public childcare or the first usage of family day care. Since mothers were interviewed in 98 percent of the cases, we restrict our sample on data provided by the biological or foster mother of the target child. We also exclude all cases who already used ECEC before wave one. ${ }^{3}$ Furthermore, since we are interested in the timing of ECEC take-up under the age of 3, our sample is based on 4 waves which cover a period of 36 months after childbirth. Observed mothers and their child are at risk from wave 1 onwards until we observe an ECEC take-up within the observed waves. Alternatively, study dropouts are right censored at the last observational time point.

Based on this approach, our sample includes 2,757 children and their mothers for whom we observe 2,052 events (i.e. childcare entries). Since the first entry to an institutional ECEC service did not occur within the observation period of 36 months, for 635 episodes we did not observe an event; hence they are right-censored. Censoring due to panel attrition occurs for 310 children and their mothers. In sum our analyses include 52,653 person-months.

In order to test our general assumptions on the impact of RC considerations on the timing of ECEC take-up, we examine to what extent mother's cost-benefit perceptions of ECEC take-up affect its timing. In a second step, we analyse heterogeneous subgroup effects with respect to East-West disparities by estimating separate models for each subgroup. Since comparing models and subgroups is central for our analysis we display our main results as average marginal effects (AME) which provide easily interpretable information (Mood, 2010). Additionally, we examine whether effects significantly differ between subgroups by using $\chi 2$ tests (Auspurg and Hinz, 2011).

\subsection{Covariates}

The central covariates in our models are the perception of different cost and benefit aspects of ECEC take-up. These rational choice parameters were developed specifically for the NEPS birth cohort study (Stocké et al., 2019), whereby operationalization of the theoretical construct was oriented on previous studies of sociological rational choice frameworks of educational decisions (Steinberg and Hoenig, 2018). Due to a strictly prospective operationalization of the RC parameters, items were measured at first wave and thus, before the majority of ECEC take-up took place.

Two dimensions of benefits regarding ECEC take-up were measured in the NEPS. The first dimension refers to the expected benefits regarding the own labour market return due to

successful. Based on these information our defined variable of public childcare take-up indicates whether the child attends a public childcare service or a family day care

${ }^{3}$ We exclude 2 percent $(n=260)$ interviewed fathers or other persons and 2 percent $(n=61)$ respondents with a child that already visited an ECEC institution before the first interview. 
ECEC usage. Expected benefits were measured by asking the mother about her own employment prospects if her child attends an ECEC institution. $\underline{1}$ The second dimension refers to the child's developmental benefit due to early education, which was measured by asking the mother to indicate the development prospects for her child if it attends an ECEC institution. In the case of both benefit dimensions, the response scales ranged from 1 (very poor prospects) to 5 (very good prospects). Table 1 presents the distribution of all covariates.

Table 1

Descriptive Statistics: Means and standard deviations

\begin{tabular}{|c|c|c|c|c|}
\hline \multirow[t]{2}{*}{ Variable } & \multicolumn{2}{|c|}{ Person-months } & \multirow[b]{2}{*}{ Min. } & \multirow[b]{2}{*}{ Max } \\
\hline & Mean & SD & & \\
\hline \multicolumn{5}{|l|}{ Benefit Expectation } \\
\hline Occupation & 4.13 & 1.14 & 1 & 5 \\
\hline Child Development & 3.90 & 1.04 & 1 & 5 \\
\hline \multicolumn{5}{|l|}{ Cost Perception } \\
\hline Financial Costs & 2.53 & 1.12 & 1 & 5 \\
\hline Social Costs & 1.77 & 1.07 & 1 & 5 \\
\hline \multicolumn{5}{|l|}{ Maternal characteristics } \\
\hline Educational Level & & & 1 & 4 \\
\hline compulsory level of education & 0.11 & 0.32 & & \\
\hline intermediate level of education & 0.26 & 0.44 & & \\
\hline maturity level of education & 0.29 & 0.45 & & \\
\hline tertiary level of education & 0.34 & 0.47 & & \\
\hline Place of birth & & & 1 & 3 \\
\hline Born in West Germany & 0.60 & 0.49 & & \\
\hline Born in East Germany & 0.18 & 0.38 & & \\
\hline Born abroad & 0.22 & 0.42 & & \\
\hline Employed: 12 months prior to birth & & & 0 & 1 \\
\hline employed & 0.71 & 0.45 & & \\
\hline not employed & 0.29 & 0.45 & & \\
\hline \multicolumn{5}{|l|}{ Household characteristics } \\
\hline Childcare provision: Grandparents no* & 0.86 & 0.34 & 0 & 1 \\
\hline Marital Status: married* & 0.74 & 0.44 & 0 & 1 \\
\hline Cohabitation: yes* & 0.94 & 0.24 & 0 & 1 \\
\hline Age of siblings living in the household* & & & 1 & 4 \\
\hline no siblings at all & 0.46 & 0.50 & & \\
\hline under or equal 3 years & 0.15 & 0.36 & & \\
\hline older than 3 years & 0.33 & 0.47 & & \\
\hline under and older than 3 years & 0.06 & 0.22 & & \\
\hline \multicolumn{5}{|l|}{ Regional indicators } \\
\hline Childcare ratio u3 (centred on state level)* & 6.73 & 14.46 & -13 & 44 \\
\hline Unemployment rate (centred on state level)* & -0.96 & 2.75 & -4.60 & 4.80 \\
\hline $\mathrm{N}$ & 52.653 & & & \\
\hline
\end{tabular}

Additionally, we analyse the relevance of two different kinds of costs associated with ECEC enrolment. First, these are financial costs based on direct expenditures for childcare. Mothers reported how strongly ECEC take-up would pose a financial burden for them. $\frac{3}{\text { In }}$ order to 
match the poling of the other dimensions, responses were reversed coded on a scale from 1 (hardly any financial burden) to 5 (strong financial burden). Second, we assume that mothers take social costs into account when deciding for ECEC take-up. Thus, mothers were asked to indicate how strongly they expect that friends and relatives would look down on them when using childcare. ${ }^{4}$ Again, responses ranged from 1 (hardly any social burden) to 5 (strong social burden).

Besides the RC parameters our covariate of main interest is the level of mother's educational attainment since we assume that social differences in the predicted determinants partly explain inequality in ECEC take-up. Based on the CASMIN (Comparative Analysis of Social Mobility in Industrial Nations) classification we distinguish four educational groups in our analyses: compulsory level of education (Hauptschulabschluss with and without vocational training: 1a-c) 11 percent, intermediate level of education (Realschulabschluss or Mittlerer Reife with and without vocational training: $2 a, b) 26$ percent, maturity level of education (Hochschulreife or Abitur: 2c) 29 percent and tertiary education (FH- or Universitätsabschluss: $3 a, b) 34$ percent.

\section{Controls}

To capture different aspects of household resources we consider marital status (married vs. not married) and cohabitation (living together vs. not living together) which can be seen as proxies for preferences regarding traditional family and childcare patterns but also give a hint regarding the opportunities of division of house and care work within couples. Both aspects might in turn influence the need for as well as the attitude towards early childcare. Against this background we also control for childcare provided by grandparents (more than $5 \mathrm{~h}$ per week) as well as the age of siblings living in the household. Former one might help to facilitate childcare at home and also later one can intensify the economic aspects for childcare at home especially when further children are younger. All household characteristics are included as wave-varying time variables.

Besides maternal education we control for further individual maternal characteristics such as the maternal employment status 12 month prior to birth expecting that mother's pre-parental labour market status influences occupational decisions also after childbirth. Owing to cultural differences in socialisation between West and East Germany we assume that preferences as well as attitudes referring to early childcare and labour market decisions differ between East and West German born mothers. Taking this into account we control for maternal birthplace differentiating between West and East Germany as well as born aboard.

Since timing of childcare take-up is not isolated from its availability, we use annual administrative records on childcare availability to measure the objective opportunity structures of ECEC. Childcare availability on county-level is thereby defined as the annual ratio of under 3-year-olds enrolled in subsidized childcare to the population of this age group, including half-day or full-day childcare centres or family day care. Since we assume that ECEC take-up is not based on actual but on preceding perception of availability we include childcare availability data as lagged variable, mean centred on state-level. To capture further regional economic aspects that might influence the demand for employment as well as public childcare, we include the centred annually unemployment rate on state-level. Both information are provided by the German Federal Statistical Office. 


\section{Results}

\section{ECEC take-up over time}

Figure 1 depicts the Kaplan-Meier failure estimator for mothers born in East or West Germany, illustrating how the proportion of children in ECEC institutions changed over the observed time of 36 months. At the start of the observation period just a few children already entered an ECEC institution. The first obvious change took place after 12 month where differences between mothers born in East or West Germany get visible. Figure 1 shows that a higher proportion of children with mothers born in East Germany started ECEC take-up earlier. Half of the observed children with East born mothers already visited an ECEC institution after 15 months. For children with West born mothers, however, applied this situation three months later. Differences between both groups decreased after 27 months but they were still significant at the end of the observation period.

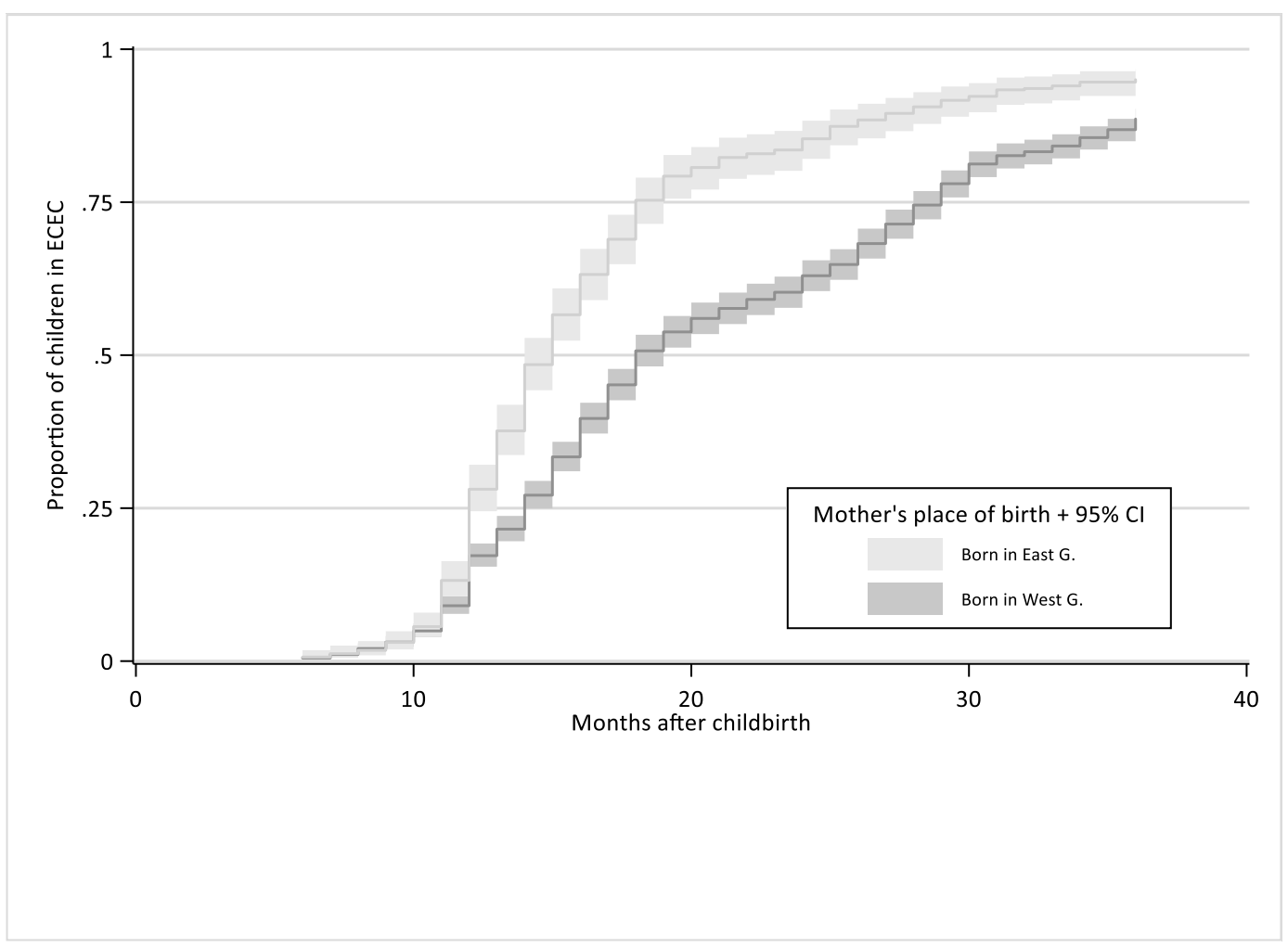

Source: doi:10.5157/NEPS:SC1:4.0.0 linked with annual regional data on county level (2011-2014), own calculations

Figure 1. Kaplan-Meier-Failure estimator: proportion of children in ECEC take-up after childbirth separated for mothers born in East or in West Germany

\section{Cost-benefit perceptions and timing of ECEC take-up}

Table 2 shows the results for the multivariate models on the determinants of timing of ECEC take-up. We separately present results for the effect of the RC parameters (M1) as well as the effect of mother's educational attainment (M2) on timing of ECEC enrolment, reporting average marginal effects (AME). Model 3 combines both, cost-benefit perceptions and educational attainment. All models include the relevant maternal, household and regional characteristics shown in Table 1 plus a monthly measure of process time. 
In general our results show that the more mothers' perceived positive benefits of ECEC the higher were their probability of an earlier ECEC take-up (M1). In actual terms, this means that a more positive maternal perception of her own occupational advantages due to ECEC attendance increases, on average, the probability of ECEC take-up by 1 percentage point in any month after childbirth. Similarly, when mothers perceive the developmental effects of early childcare more positive the probability of ECEC take-up increases also by 1 percentage point in any month after birth. This implies that a higher perception of childcare benefits regarding the occupational prospects as well as child's enrichment is responsible for an earlier ECEC take-up in Germany. Model 3 confirms this finding and provides support our assumption that benefit perceptions of ECEC make an earlier ECEC enrolment more likely.

Contrary to our expectations, Model 1 and 3 demonstrate that higher perceived social and financial burdens of ECEC did not induce a significant later take-up of ECEC. Our results show in any of the models no statistically relevant association between ECEC timing and maternal perception of financial or social childcare costs.

The findings for maternal education confirm, that a higher maternal educational degree raised the probability of an earlier ECEC usage (M2 and M3). For example, for mothers with a tertiary degree the probability of ECEC take-up increases by 2 percent points in any month after birth compared to the reference group of mothers with an intermediate level of education. Similarly, mothers with a maturity level of education have a higher probability of an earlier ECEC take-up, whereas mothers with a compulsory level of education have a higher probability of a later ECEC take-up in comparison to the reference group. In Model 3 net effects of education were still strongly associated with the timing of ECEC take-up.

Table 2

Perception of ECEC cost-benefit parameters and timing of ECEC take-up, discrete models

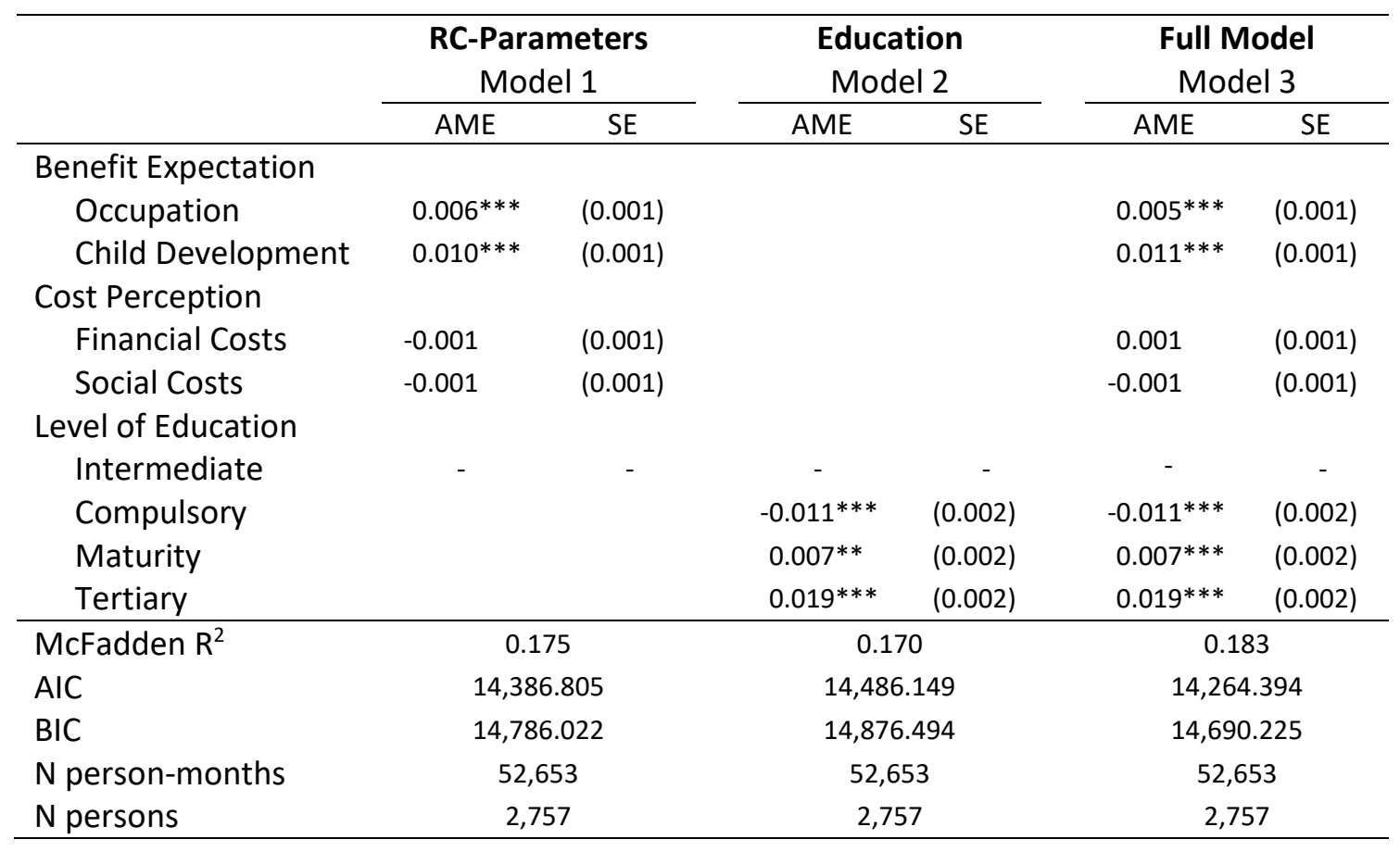

Note: Models include maternal, household, regional controls, and time. Significance levels: $+p<0.10,{ }^{*} p<0.05,{ }^{* *} p<0.01,{ }^{* * *} p<0.001$ Source: doi:10.5157/NEPS:SC1:4.0.0 linked with annual regional data on county level (2011-2014), own calculations 


\section{Heterogeneous group effects}

We estimate separate models to distinguish whether the direct effects of RC parameters vary between mothers from East or West Germany (Table 3 ). Besides the average marginal effects, table 3 shows also results of $\chi 2$-tests referring to effect differences between the respective subgroups.

We found differences in the perception of occupational benefits between East and West German born mothers. For mothers born in West Germany (M4) perceived positive occupational advantages due to ECEC usage were more relevant for the timing of ECEC takeup than for mothers born in East Germany (M5). However, comparing the effect differences $\chi 2$-test showed no significant difference of the perceived occupational benefit effect and its association with timing of ECEC take-up.

Table 3

Perception of ECEC cost-benefit parameters and timing of ECEC take-up for mothers born in West or East Germany, discrete models

\begin{tabular}{|c|c|c|c|c|c|}
\hline & \multicolumn{4}{|c|}{ Effects } & \multirow{2}{*}{$\begin{array}{c}\text { Effect } \\
\text { Differences } \\
\chi 2 \text { tests }\end{array}$} \\
\hline & \multirow{2}{*}{\multicolumn{2}{|c|}{$\begin{array}{c}\text { Born in West } \\
\text { Germany } \\
\text { Model } 4\end{array}$}} & \multirow{2}{*}{\multicolumn{2}{|c|}{$\begin{array}{c}\text { Born in East } \\
\text { Germany } \\
\text { Model } 5\end{array}$}} & \\
\hline & & & & & \\
\hline & AME & SE & AME & SE & \\
\hline \multicolumn{6}{|l|}{ Benefit Expectation } \\
\hline Occupation & $0.006^{* * *}$ & 0.001 & 0.004 & 0.003 & 2.500 \\
\hline Child Development & $0.012^{* * *}$ & 0.001 & $0.014^{* * *}$ & 0.003 & 2.500 \\
\hline \multicolumn{6}{|l|}{ Cost Perception } \\
\hline Financial Costs & 0.001 & 0.001 & -0.001 & 0.002 & 0.200 \\
\hline Social Costs & -0.000 & 0.001 & $-0.009 * *$ & 0.003 & $8.100^{* *}$ \\
\hline \multicolumn{6}{|l|}{ Educational attainment } \\
\hline Intermediate & - & - & - & - & - \\
\hline Compulsory & $-0.014^{* * *}$ & 0.003 & $-0.017^{*}$ & 0.007 & 0.431 \\
\hline Maturity & $0.008^{* *}$ & 0.003 & 0.002 & 0.006 & 1.089 \\
\hline Tertiary & $0.020 * *$ & 0.003 & $0.016 *$ & 0.006 & 0.356 \\
\hline McFadden $\mathrm{R}^{2}$ & \multicolumn{2}{|c|}{0.172} & \multicolumn{2}{|c|}{0.249} & \\
\hline AIC & \multicolumn{2}{|c|}{$8,757.844$} & \multicolumn{2}{|c|}{$2,935.560$} & \\
\hline $\mathrm{BIC}$ & \multicolumn{2}{|c|}{$9,142.438$} & \multicolumn{2}{|c|}{$3,256.356$} & \\
\hline $\mathrm{N}$ person-months & \multicolumn{2}{|c|}{31,594} & \multicolumn{2}{|c|}{9,217} & \\
\hline $\mathrm{N}$ persons & \multicolumn{2}{|c|}{1,600} & \multicolumn{2}{|c|}{596} & \\
\hline
\end{tabular}

Note: Models include maternal, household, regional controls, and time. Significance levels: $+p<0.10,{ }^{*} p<0.05, * * p<0.01, * * * p<0.001$ Source: doi:10.5157/NEPS:SC1:4.0.0 linked with annual regional data on county level (2011-2014), own calculations

We found no differences in the perceived positive developmental effect and the association on timing of ECEC take-up for East and West German born mothers. Although the effect did not differ significantly, effect sizes tended to be stronger for the East German sample.

Lastly, results reveal a surprisingly negative association between perceived social costs and timing of ECEC take-up for mothers born in East Germany. While mothers from East Germany took perceived social cost into account when considering the timing of ECEC take-up, West German born mothers did not. Looking at the $\chi 2$-test we saw a significant difference of this effect between both groups. However, financial burdens showed no statistically relevant 
association regarding the probability of timing of ECEC take-up in any subgroup. In general, effects of mothers' educational attainment seemed to be more relevant for the timing of ECEC take-up in West than in East Germany, however the difference was statistically insignificant.

\section{Summary and conclusion}

This study represents the first application of sociological rational choice theory on explaining the mechanisms of social selective ECEC usage for under threes in Germany. By focusing on the timing of ECEC take-up, it investigates whether and to which extent take-up of public childcare is associated with cost-benefit perceptions of childcare. The analyses provide evidence that firstly, the decision to take-up formal childcare is based on rational motivated cost-benefit considerations. Mothers seem to pay particular attention to benefit considerations, as mothers who perceive ECEC usage as an educational decision for their child as well as an opportunity to maintain their own labour market participation take up ECEC earlier. Secondly, we demonstrate that in Germany not only the decision to use but also the timing of ECEC take-up is socially selective. Mothers with a higher level of educational attainment have a higher probability of an earlier ECEC take-up. However, controlling for RC parameters does not explain these educational disparities in the timing of ECEC take-up. Thirdly, we find that the perception of financial ECEC costs are not associated with the timing of ECEC enrolment. In general, low public childcare costs in the German childcare system might explain why rational considerations about the timing of ECEC take-up are not affected by the perception of this dimension. Since in the German context a lack of availability might be perceived as more problematic than financial burdens the perceived availability would therefore be a useful dimension for further RC motivated research. Furthermore, we do not find an effect of social childcare costs in the full model.

Apart from this broad pattern, we also question whether direct effects of RC parameters vary among East and West German born mothers, assuming that they vary especially in their cultural socialisations experiences. Findings indicate that persistent East-West differences in culture and gender ideologies moderate the relevance of cost-benefit perceptions for the timing of ECEC take-up. Comparisons of both groups show that perceived occupational benefits due to early childcare usage are considered from mothers born in West but not in East Germany. Aspects regarding perceived benefits of child's enrichment owing to ECEC takeup have a relevant impact for the timing of ECEC take-up independently of mother's birthplace.

Disparities regarding the perceived occupational advantages du to ECEC between East and West German born mothers may suggest that mothers born in West Germany so far hold on to more traditional work-care norms with a weaker attachment to the labour market (Konietzka and Kreyenfeld, 2010). Thus, considerations of occupational benefits owing to ECEC are more relevant for their timing of ECEC take-up. Conversely, for mothers grown up in East Germany shorter labour market interruptions after childbirth as well as a general high female labour market participation are the norm (Rosenfeld, Trappe and Gornick, 2004). In view of the already comparatively short interruptions and the still moderate career opportunities in the East German labour market, mothers might not expect any further advantages from an even earlier return to the labour market. Due to this circumstance occupational benefits of ECEC enrolment are less relevant for East German mothers' considerations of ECEC timing. 
Today ECEC is viewed more and more as early education whereas formerly it was regarded mainly as institution of seakeeping and caring. That mothers irrespective of their birthplace take this aspect similarly into account underlines this indication. Since the aspect of early education is also relevant for the timing of ECEC take-up for mothers born in East Germany despite their longer socialisation with and acceptance of ECEC systems.

However, that social costs negatively associated with timing of ECEC only for East German born mothers comes as somewhat of a surprise. This result suggests that disparities in norm internalization due to different socialisation experiences might not be the only reason why East and West German born mothers differ in their cost-benefit perception of ECEC take-up. Alternatively, this result might indicate that the norm internalization among mothers grown up in East Germany relates only to attitudes towards employment participation but not towards early childcare per se.

By applying sociological RC motivated considerations the present study makes an important contribution to explain mechanisms of social inequalities in ECEC attendance for children under the age of three. Yet, some important limitations need to be taken into account: A small sample size, especially of the lower educated mothers, did not allow us to run separate models for the educational subgroups in East and West Germany. As a further limitation, we cannot rule out that childcare enrolment has been restricted due to a lack of availability or not gaining priority access for example due to dual-earner parents. Possibly differences in maternal or parental characteristics such as their knowledge about the childcare system or their social networks might also have an effect on their awareness of ECEC. Moreover, the risk of biased estimates remains also due to other unobserved characterises such as the relevance of ECEC quality.

Despite these limitations, our findings provide evidence that mothers perceive ECEC usage as an educational decision for their child as well as for their own employment career. Thus, sociological frameworks of rational choice theory on educational decision can explain social inequalities on timing of ECEC take-up to some extent. Since our data are the first application of a RC motivated childcare decision further research would gain from measurement of perceived availability of early childcare since ECEC demand in Germany still exceeds supply despite the legal entitlement to childcare. Future studies should furthermore draw on parental search strategies as well as their knowledge regarding their childcare rights to reveal further mechanisms leading to social selective ECEC take-up.

\section{Acknowledgements}

The authors would like to thank Gundula Zoch and the participants of the research seminar at the Leibniz Institute for Educational Trajectories in Bamberg for their valuable comments. 


\section{References}

Allison, P. D. (1982). Discrete-Time Methods for the Analysis of Event Histories. Sociological Methodology, 13, 61.

Allison, P. D. (2010). Survival analysis using SAS: A practical guide. Cary, N.C: SAS Institute.

Anderson, L. M., Shinn, C., Fullilove, M. T., Scrimshaw, S. C., Fielding, J. E., Normand, J. and Carande-Kulis, V. G. (2003). The effectiveness of early childhood development programs. American Journal of Preventive Medicine, 24(3), 32-46.

Auspurg, K. and Hinz, T. (2011). Gruppenvergleiche bei Regressionen mit binären abhängigen Variablen - Probleme und Fehleinschätzungen am Beispiel von Bildungschancen im Kohortenverlauf. Zeitschrift für Soziologie, 40(1), 186.

Bainbridge, J., Meyers, M. K., Tanaka, S. and Waldfogel, J. (2005). Who Gets an Early Education? Family Income and the Enrollment of Three- to Five-Year-Olds from 1968 to 2000 Social Science Quarterly, 86(3), 724-745.

Blossfeld, H.-P., \& Rossbach, H.-G. (Eds.). (2019). Education as a Lifelong Process: The German National Educational Panel Study (NEPS). Wiesbaden: Springer Fachmedien Wiesbaden.

Büchner, C. and Spiess, C. K. (2007). Die Dauer vorschulischer Betreuungs- und Bildungserfahrungen: Ergebnisse auf der Basis von Paneldaten. DIW Discussion Papers 687. Berlin.

Bundesministerium für Familie, Senioren, Frauen und Jugend (BMFSFJ) (2018). Kindertagesbetreuung Kompakt. Ausbaustand und Bedarf 2017. Berlin.

Burger, K. (2010). How does early childhood care and education affect cognitive development? An international review of the effects of early interventions for children from different social backgrounds. Early childhood research quarterly, 25(2), 140-165.

Chaudry, A., Henly, J. R. and Meyers, M. K. (2010). Conceptual Frameworks for Child Care Decision-Making. ACF-OPRE White Paper. Washington, DC.

Coley, R. L., Votruba-Drzal, E., Collins, M. A. and Miller, P. (2014). Selection into early education and care settings: Differences by developmental period. Early childhood research quarterly, 29(3), 319-332.

Côté, S. M., Doyle, O., Petitclerc, A. and Timmins, L. (2013). Child care in infancy and cognitive performance until middle childhood in the millennium cohort study. Child Development, 84(4), 1191-1208.

Crosnoe, R., Purtell, K. M., Davis-Kean, P., Ansari, A. and Benner, A. D. (2016). The selection of children from low-income families into preschool. Developmental Psychology, 52(4), 599612.

Del Boca, D., Locatelli, M. and Vuri, D. (2005). Child-Care Choices by Working Mothers: The Case of Italy. Review of Economics of the Household, 3(4), 453-477.

Dowsett, C. J., Huston, A. C. and Imes, A. E. (2008). Structural and Process Features in Three Types of Child Care for Children from High and Low Income Families. Early Childhood Research Quarterly, 23(1), 69-93.

Early, D. M. and Burchinal, M. R. (2001). Early childhood care: relations with family characteristicsand preferred care characteristics. Early childhood research quarterly, 16(4), 475-497.

Geoffroy, M.-C., Côté, S. M., Giguère, C.-É., Dionne, G., Zelazo, P. D., Tremblay, R. E., Boivin, M. and Séguin, J. R. (2010). Closing the gap in academic readiness and achievement: the 
role of early childcare. Journal of Child Psychology and Psychiatry, and Allied Disciplines, 51(12), 1359-1367.

Hachul, C., Attig, M., Lorenz, J., Weinert, S., Schneider, T. and Rossbach, H.-G. (2019). From Birth to Early Child Care: The Newborn Cohort Study of the National Educational Panel Study. In H.-P. Blossfeld \& H.-G. Rossbach (Eds.), Education as a Lifelong Process: The German National Educational Panel Study (NEPS) (pp. 195-214). Wiesbaden: Springer Fachmedien Wiesbaden.

Konietzka, D. and Kreyenfeld, M. (2010). The growing educational divide in mothers' employment: An investigation based on the German micro-censuses 1976-2004. Work, employment and society, 24(2), 260-278.

Krapf, S. (2014). Who uses public childcare for 2-year-old children? Coherent family policies and usage patterns in Sweden, Finland and Western Germany. International Journal of Social Welfare, 23(1), 25-40.

Kreyenfeld, M. and Krapf, S. (2016). Soziale Ungleichheit und Kinderbetreuung - Eine Analyse der sozialen und ökonomischen Determinanten der Nutzung von Kindertageseinrichtungen. In R. Becker \& W. Lauterbach (Eds.), Bildung als Privileg: Erklärungen und Befunde zu den Ursachen der Bildungsungleichheit (5th ed., pp. 119-144). Wiesbaden: Springer VS.

Loeb, S., Bridges, M., Bassok, D., Fuller, B. and Rumberger, R. W. (2007). How much is too much? The influence of preschool centers on children's social and cognitive development. Economics of Education Review, 26(1), 52-66.

Magnuson, K. A., Meyers, M. K., Ruhm, C. J. and Waldfogel, J. (2016). Inequality in Preschool Education and School Readiness. American Educational Research Journal, 41(1), 115-157.

Meyers, M. K. and Jordan, L. P. (2006). Choice and Accommodation in Parental Child Care Decisions. Community Development, 37(2), 53-70.

Mood, C. (2010). Logistic Regression: Why We Cannot Do What We Think We Can Do, and What We Can Do About It. European Sociological Review, 26(1), 67-82.

Morrissey, T. W. (2017). Child care and parent labor force participation: A review of the research literature. Review of Economics of the Household, 15(1), 1-24.

NICHD Early Child Care Research Network (1997). Familial Factors Associated with the Characteristics of Nonmaternal Care for Infants. Journal of Marriage and the Family, 59(2), 389-408.

Petitclerc, A., Côté, S., Doyle, O., Burchinal, M., Herba, C., Zachrisson, H. D., Boivin, M., Tremblay, R. E., Tiemeier, H., Jaddoe, V. and Raat, H. (2017). Who uses early childhood education and care services? Comparing socioeconomic selection across five western policy contexts. International Journal of Child Care and Education Policy, 11(1), 487.

Rosenfeld, R. A., Trappe, H. and Gornick, J. C. (2004). Gender and Work in Germany: Before and After Reunification. Annual Review of Sociology, 30(1), 103-124.

Schober, P. S. and Spiess, C. K. (2012). Frühe Förderung und Betreuung von Kindern: Bedeutende Unterschiede bei der Inanspruchnahme besonders in den ersten Lebensjahren. DIW Wochenbericht, 43, 17-28.

Schober, P. S. and Spiess, C. K. (2013). Early Childhood Education Activities and Care Arrangements of Disadvantaged Children in Germany. Child Indicators Research, 6(4), 709735. 
Schober, P. S. and Stahl, J. F. (2014). Childcare Trends in Germany- Increasing Socio-Economic Disparities in East and West. DIW Economic Bulletin, 4, 51-58.

Singer, J. D. and Willett, J. B. (2003). Applied longitudinal data analysis: Modeling change and event occurrence. Oxford: Oxford Univ. Press.

Spiess, C. K., Berger, E. M. and Groh-Samberg, O. (2008). Overcoming Disparities and Expanding Access to Early Childhood Services in Germany: Policy Considerations and Funding Options. UNICEF Innocenti Research Centre Working Paper IWP-2008-03. Florence.

Stahl, J. F., Schober, P. S. and Spiess, C. K. (2018). Parental socio-economic status and childcare quality: Early inequalities in educational opportunity? Early childhood research quarterly, 44(3), 304-317.

Stahl, J. F. and Schober, P. S. (2018). Convergence or Divergence? Educational Discrepancies in Work-Care Arrangements of Mothers with Young Children in Germany. Work, employment and society, 32(4), 629-649.

Steinberg, H. and Hoenig, K. (2018). Measuring rational educational choices in NEPS (NEPS Survey Paper No. 49). Bamberg, Germany: Leibniz Institute for Educational Trajectories, National Educational Panel Study.

Stocké, V., Blossfeld, H.-P., Hoenig, K. and Sixt, M. (2019). Social Inequality and Educational Decisions in the Life Course. In H.-P. Blossfeld \& H.-G. Rossbach (Eds.), Education as a Lifelong Process: The German National Educational Panel Study (NEPS) (pp. 101-118). Wiesbaden: Springer Fachmedien Wiesbaden.

Sylva, K., Stein, A., Leach, P., Barnes, J. and Malmberg, L.-E. (2007). Family and child factors related to the use of non-maternal infant care: An English study. Early childhood research quarterly, 22(1), 118-136.

Sylva, K., Stein, A., Leach, P., Barnes, J. and Malmberg, L.-E. (2011). Effects of early child-care on cognition, language, and task-related behaviours at 18 months: An English study. The British Journal of Developmental Psychology, 29(1), 18-45.

Van Gameren, E. and Ooms, I. (2009). Childcare and labor force participation in the Netherlands: The importance of attitudes and opinions. Review of Economics of the Household, 7(4), 395-421.

Wrohlich, K. (2011). Labor Supply and Child Care Choices in a Rationed Child Care Market. DIW Discussion Papers, 1169.

Zachrisson, H. D., Janson, H. and Nærde, A. (2013). Predicting early center care utilization in a context of universal access. Early childhood research quarterly, 28(1), 74-82. 


\section{Appendix}

For the following questions see Steinberg and Hoenig (2018) and Blossfeld and Rossbach (2019):

1. Question: For the following questions, imagine that your child was attending day care. What would this mean for your child and yourself? How good are the prospects of you being employed if your child attended day care?

2. Question: How good are the prospects of your child developing if he/she attended day care?

3. Question: Attendance of a day care incurs a variety of costs, such as fees, money for materials and travel costs. How difficult would you find it to pay the costs incurred as a result of your child attending day care?

4. Question: To what extent does the following statement apply to you? If I were to send my child to a day care, my friends and relatives would look down on me. 